\title{
Comparison of the Effectiveness of Min Dfulness- Based Cognitive Therapy with Compassion- Focused Therapy on Resilience and Psychological Well- Being of Subjects with Multiple Sclerosis
}

Morteza Akbarpour ${ }^{1}$, Maryam Sharifiyan Ghazijahani ${ }^{1}$, Hadi Smkhani Akbarinejhad ${ }^{\text {* }}$

${ }^{1}$ Department of Clinical Psychology, Science and Research Branch, Islamic Azad University, Tabriz, Iran

${ }^{2}$ Department of Psychology, University College of Nabi Akram, Tabriz, Iran

\section{A BSTRACT}

Introduction: As multiple sclerosis (MS) affects both the body and mind, people with MS need to be treated by both pharmacological and psychological interventions. Psychological interventions include using a variety of counseling and psychotherapy approaches, such as mindfulness- based cognitive therapy and compassion-focused therapy. The purpose of this study was to compare the efficacy of mindfulness- based cognitive therapy and compassionfocused therapy on resilience and psychological well- being in patients with MS. Materials and Methods: This study was semi-experimental with a pre- test, post- test control group design. This study consisted of all men with MS in Tabriz who were members of the MS Society in 2018. In total, 30 men were selected and randomly divided into three groups by a purposive sampling method. Members of both experimental groups received their treatment, respectively, in eight sessions of 1.5 hours; however, the control group did not receive any treatment. Results: There was no significant difference between resilience and psychological well-being scores in the treatment and control groups in the pre-test. The results showed that mindfulness- based cognitive therapy and compassion-focused therapy compared to the control group led to increased resilience \& psychological wellbeing in MS patients in the post- test. In the follow-up phase, the effect of mindfulnessbased cognitive therapy and compassion-focused therapy on resilience and psychological well-being persisted. Furthermore, the impact of mindfulness-based cognitive therapy and compassion-focused therapy on resilience and psychological well-being in the post-test and follow- up was significantly not different. Conclusion: Mindfulness-based cognitive therapy and compassion-focused therapy are likely to reduce anxiety, thereby better coping with the disease and increasing resilience and psychological well- being in patients with MS.

\section{Keywords:}

1. Cognitive Behavioral Therapy 2. Multiple Sclerosis

3. Psychosocial Intervention

*Corresponding Author: Hadi Smkhani Akbarinejhad

Email: Hadiakbarinejhad@yahoo.com 


\title{
مقايسةٌ اثربخشى شناختدرمانى مبتنى بر ذهن آكاهى با درمان متمركز بر شفقت بر تاب آورى و

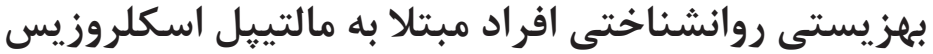

\author{
مر تضى اكبر يور'، مريم شريفيان قاضى جهانى'، هادى اسمخانى اكبرىنزاد"r

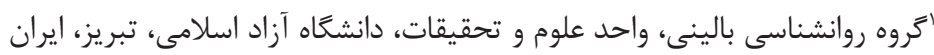

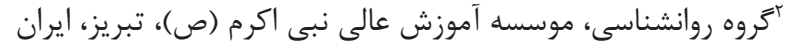

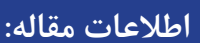

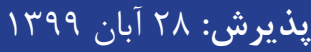

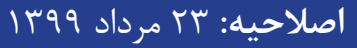

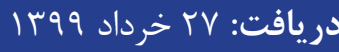

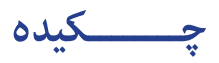

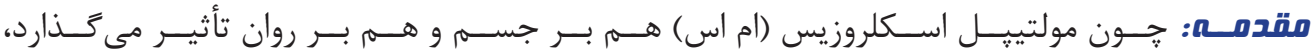

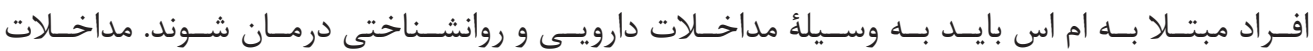

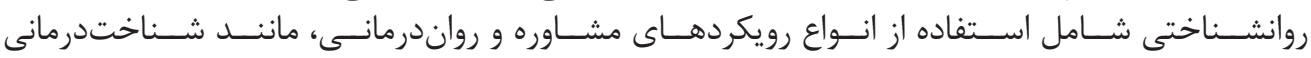

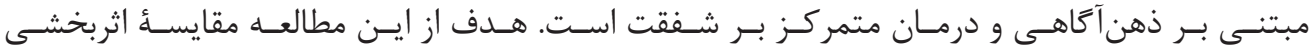

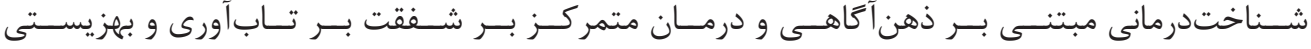

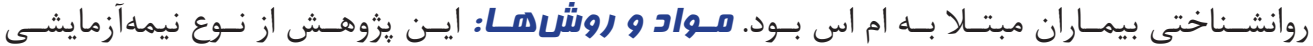

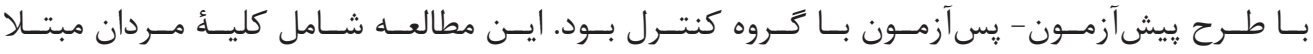

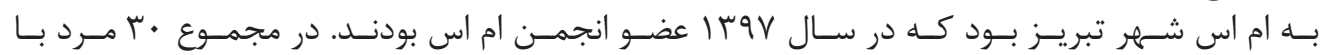

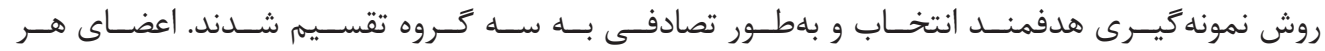

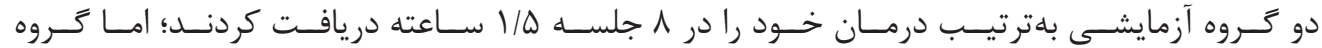

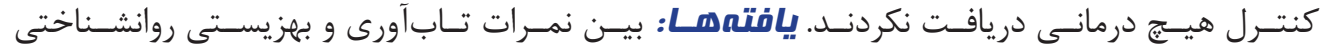

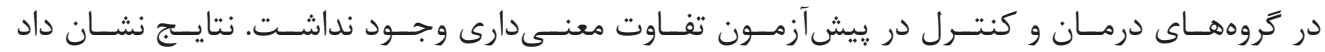

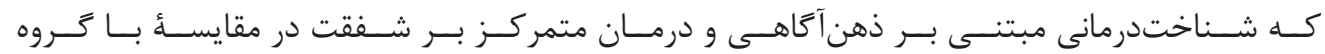

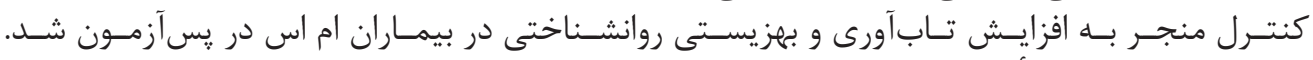

وازههاى كليدى:

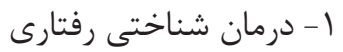

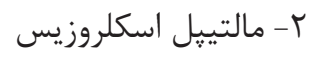

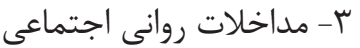

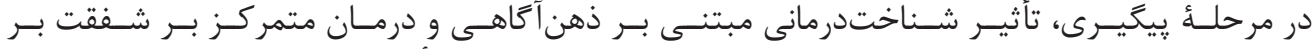

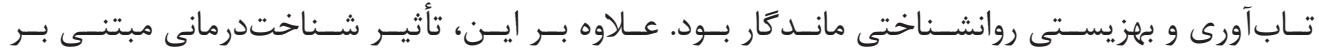

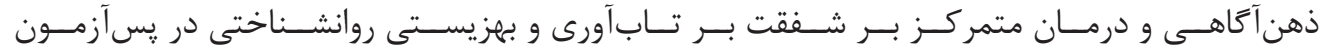

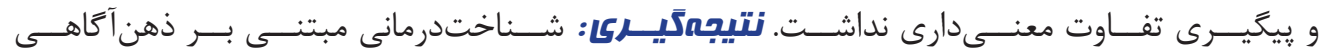

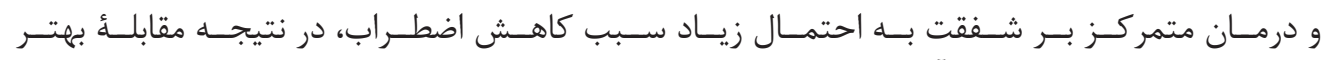

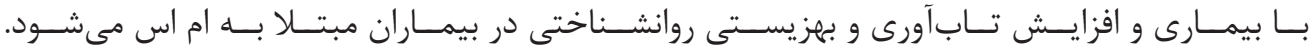




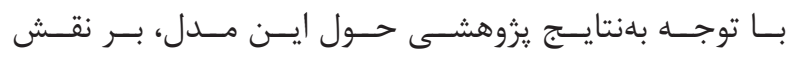

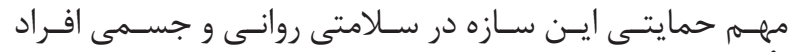

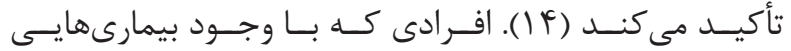

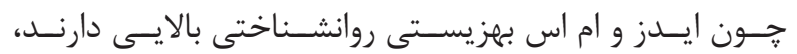

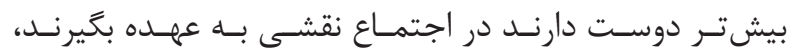

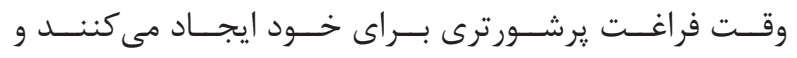

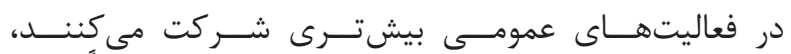

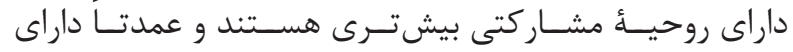

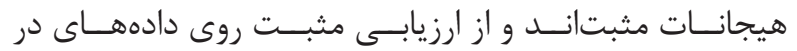

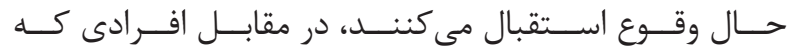

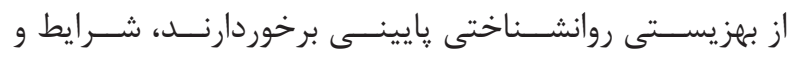

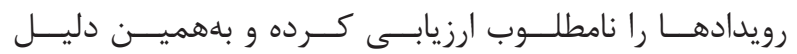

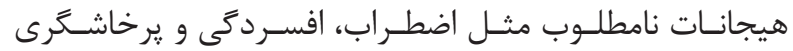

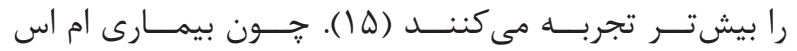

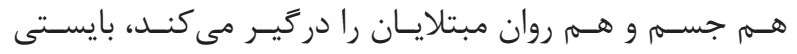

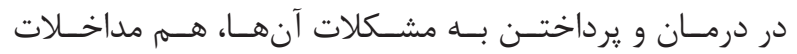

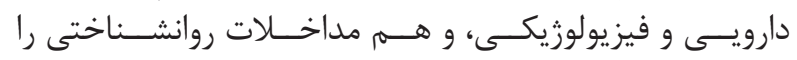

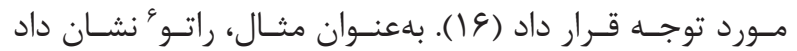

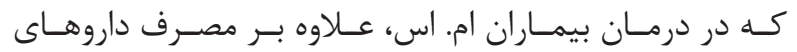

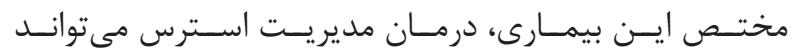

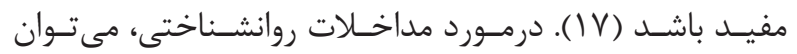

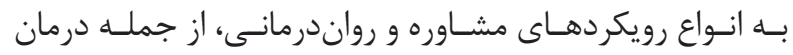

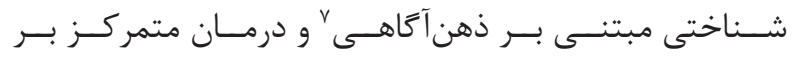

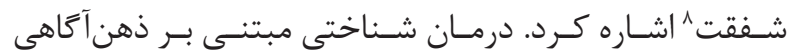

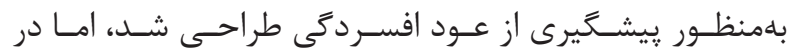

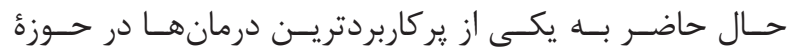

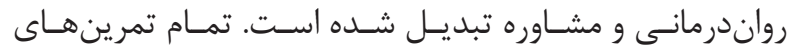

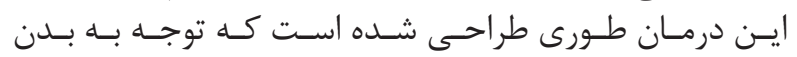

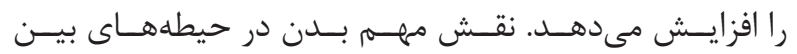

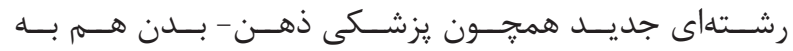

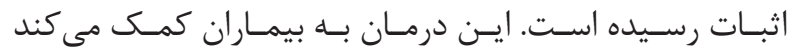

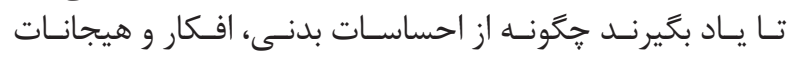

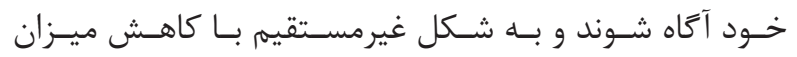

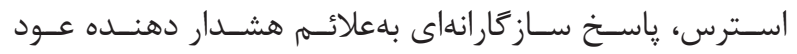

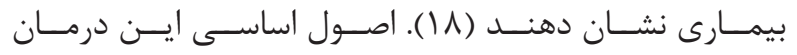

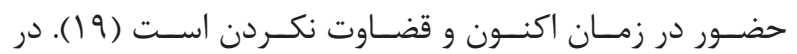

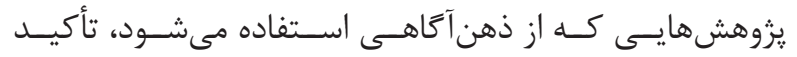

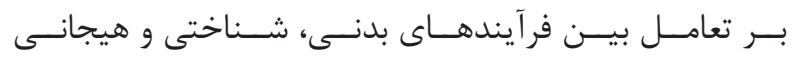

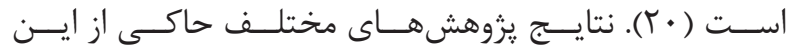

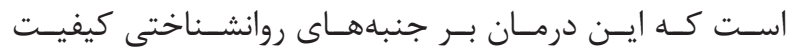

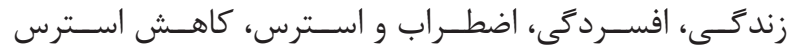

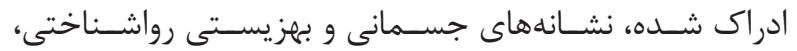

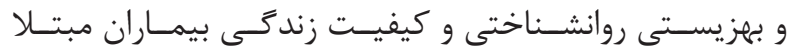

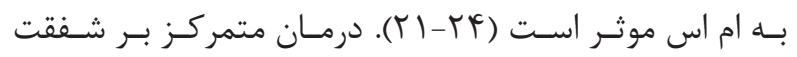

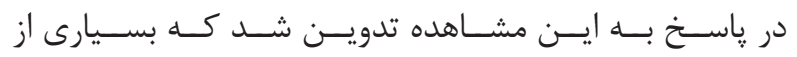

${ }^{1}$ Multiple Sclerosis

${ }^{2}$ Resilience

${ }^{3}$ Weiss, Westerhof \& Bohlmeijer

${ }^{4}$ Psychological Well- Being

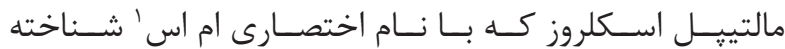

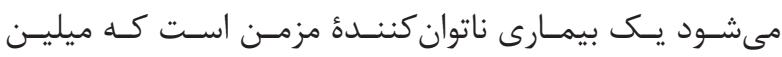

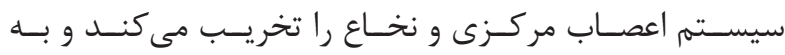

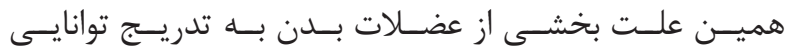

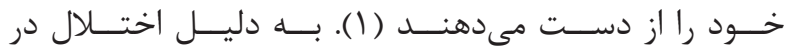

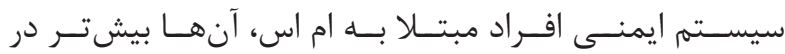

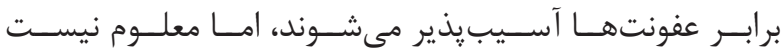

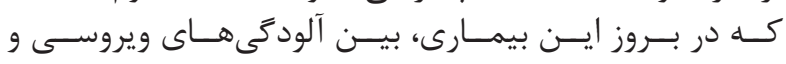

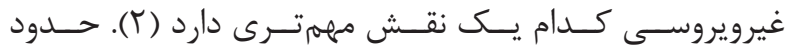

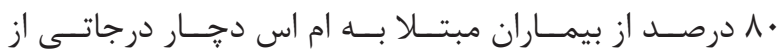

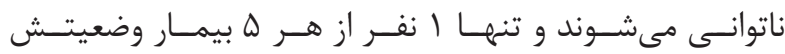

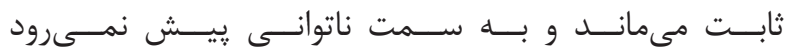

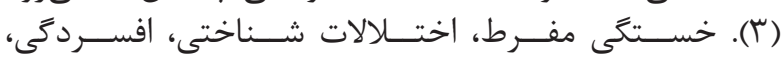

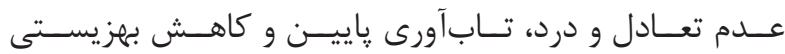

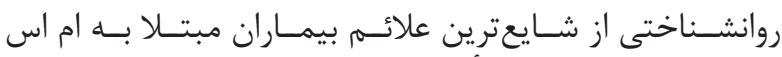

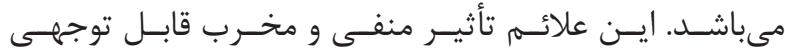

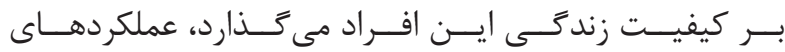

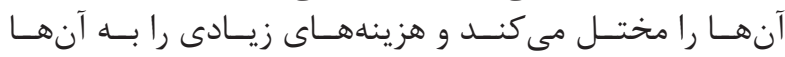

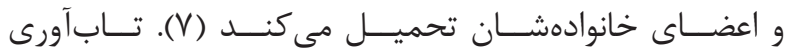

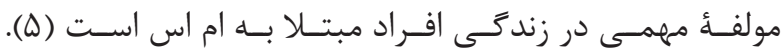

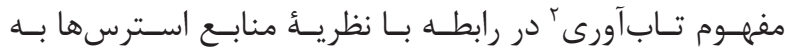

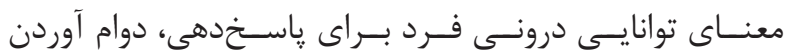

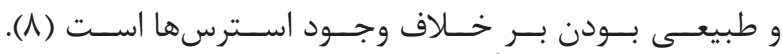

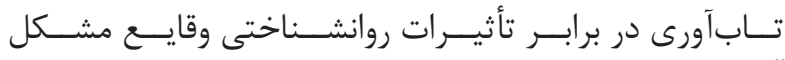

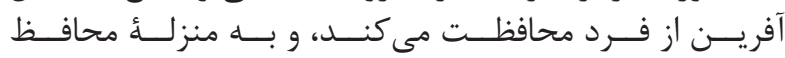

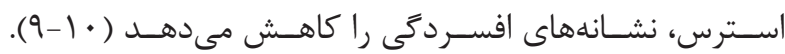

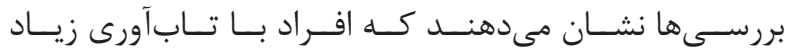

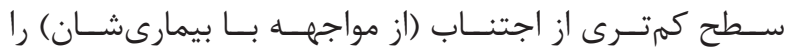

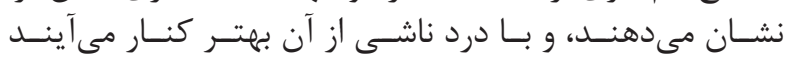

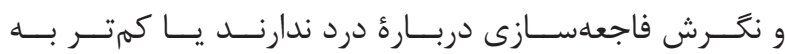

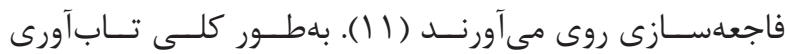

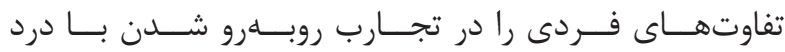

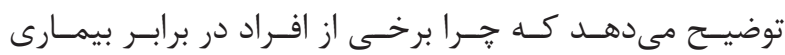

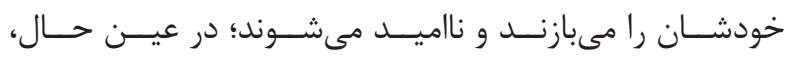

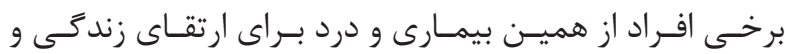

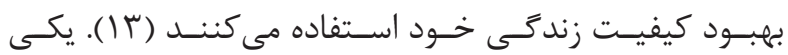

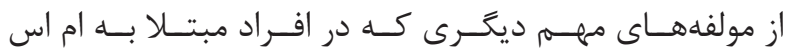

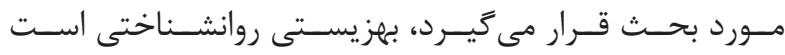

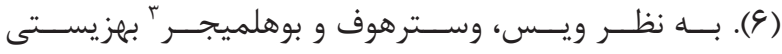

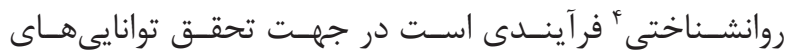

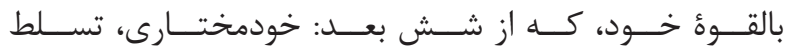

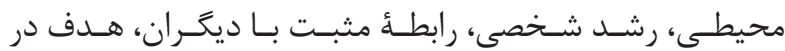

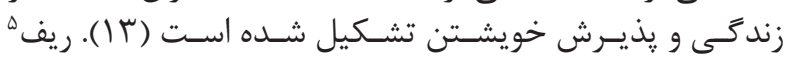

\footnotetext{
${ }^{5}$ Ryff

${ }^{6}$ Rattue

${ }^{7}$ Mindfulness- Based Cognitive Therapy

${ }^{8}$ Compassion-Focused Treatment
} 


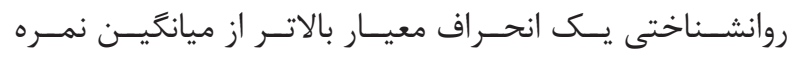

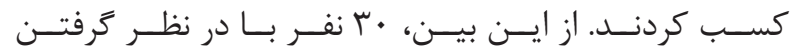

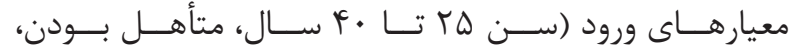

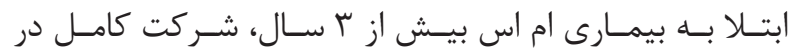

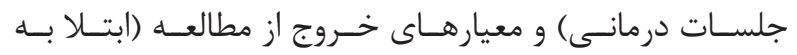

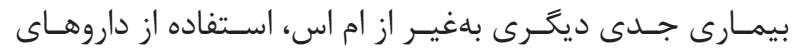

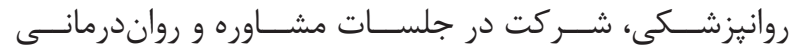

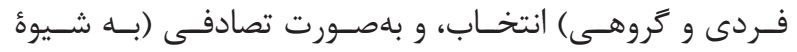

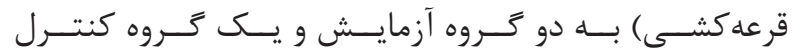

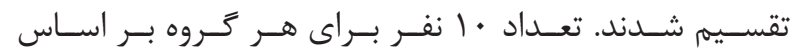

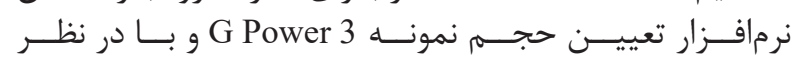

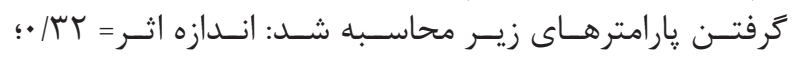

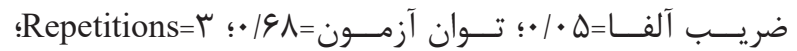
Critical $F=r / \bullet 11$ ! $\mid$ Noncentrality parameter $\lambda=/ r \cdot 9$ Actual $=\cdot|\Lambda|$ Denominator $\mathrm{df}=r \mathcal{r}$ ؛Numerator $\mathrm{df}=r$

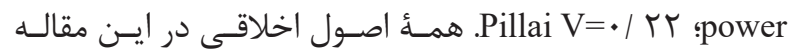

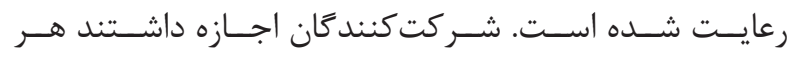

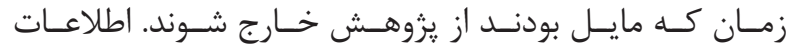

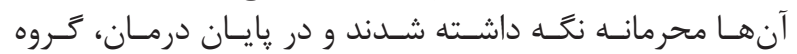

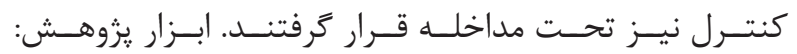

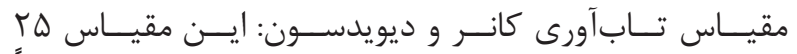

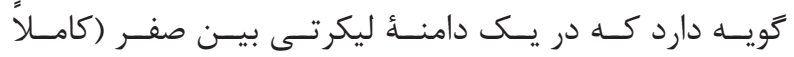

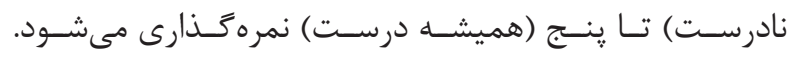

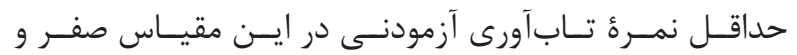

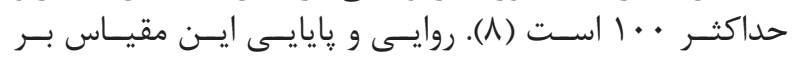

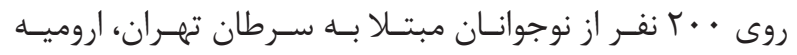

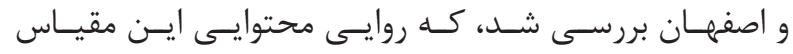

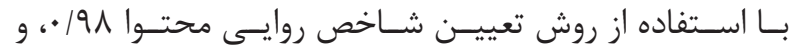

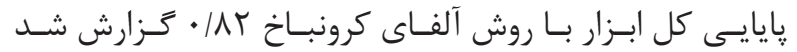

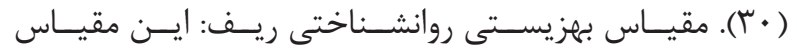

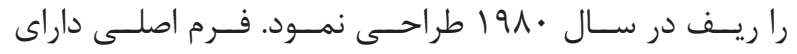

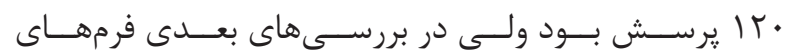

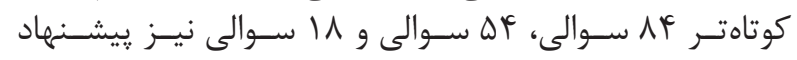

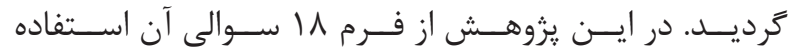

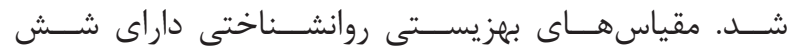

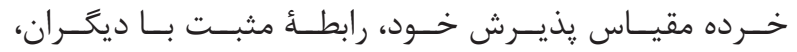

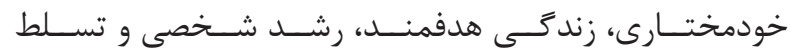

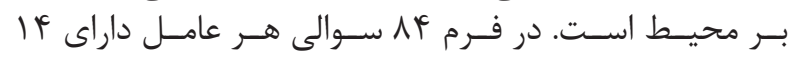

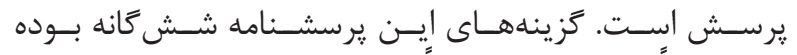

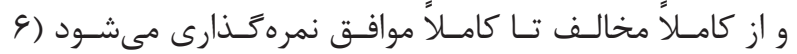

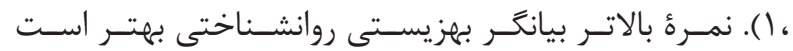

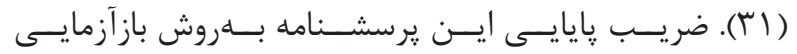

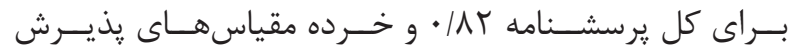

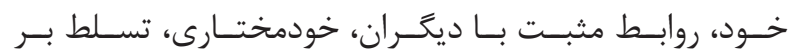

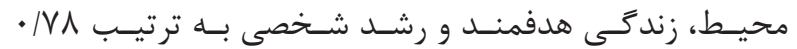

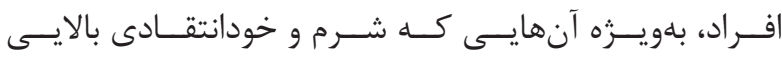

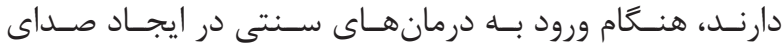

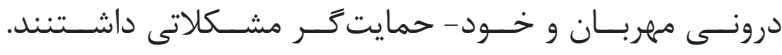

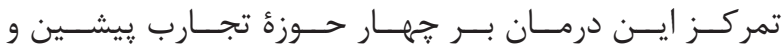

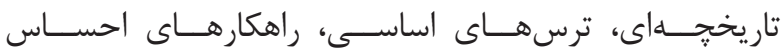

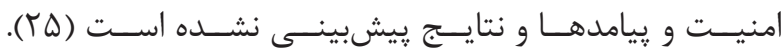

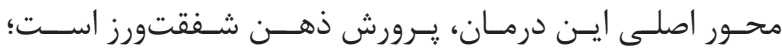

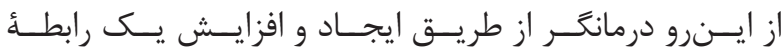

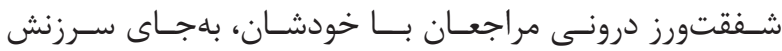

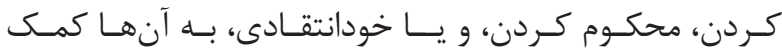

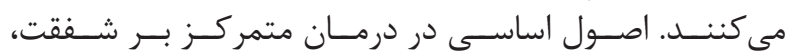

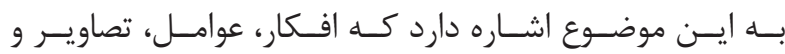

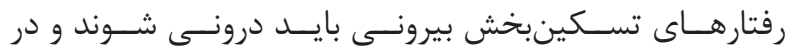

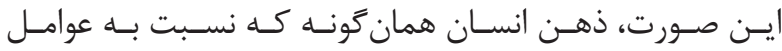

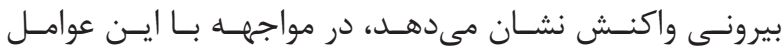

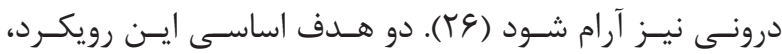

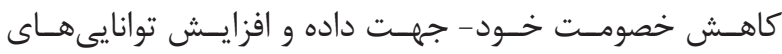

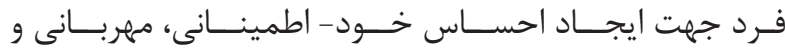

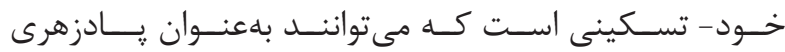

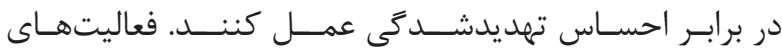

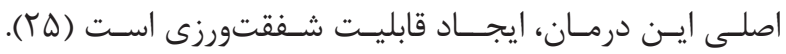

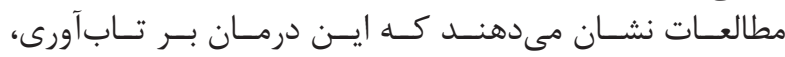

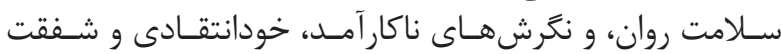

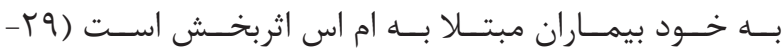

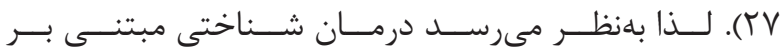

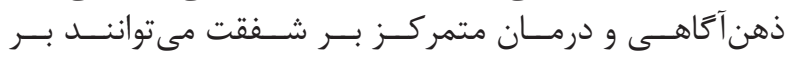

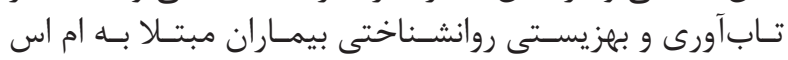

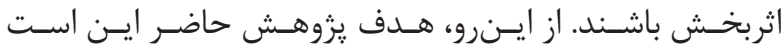

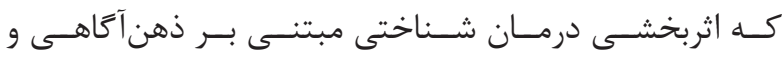

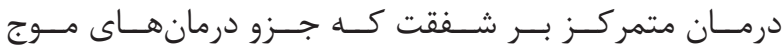

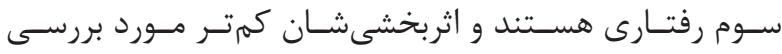

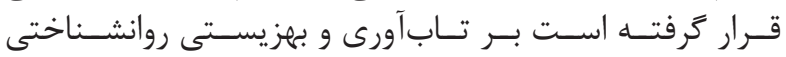

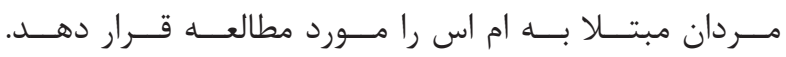

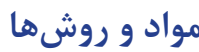

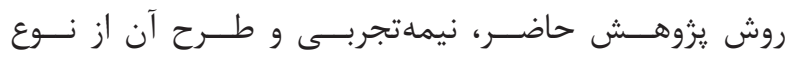

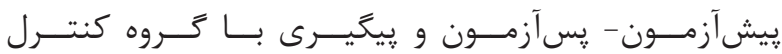

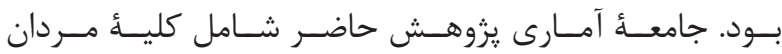

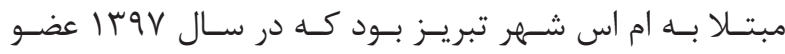

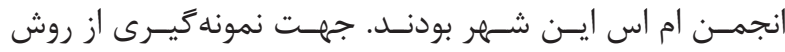

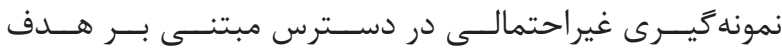

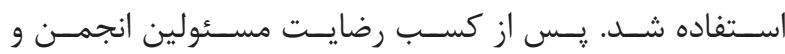

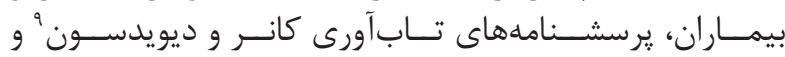

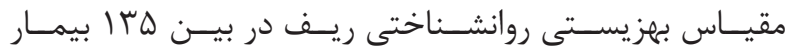

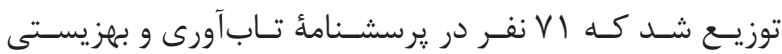

${ }^{9}$ Connor and Davidson 


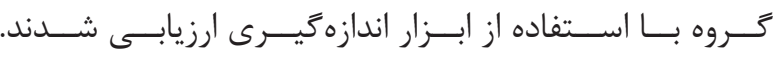

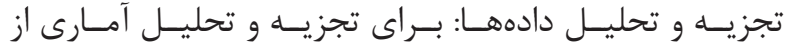

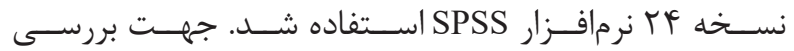

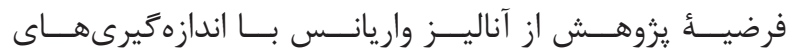

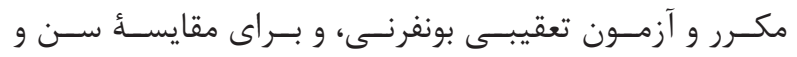

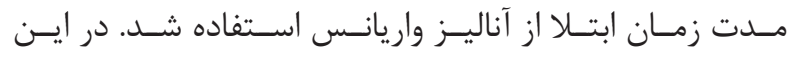

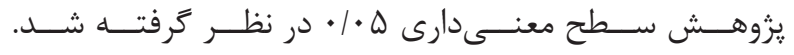

بافته ها

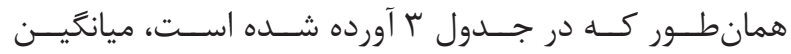

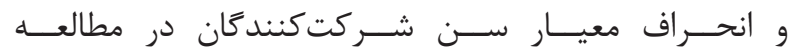
9

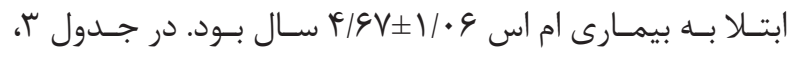

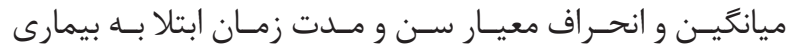

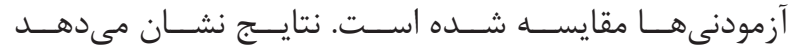

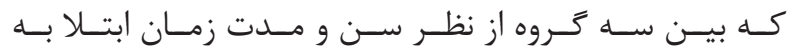

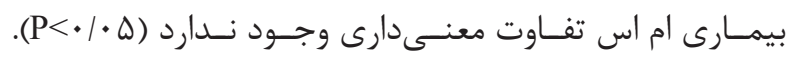

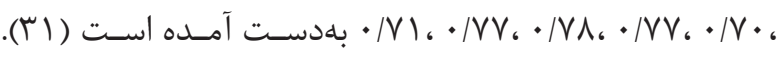

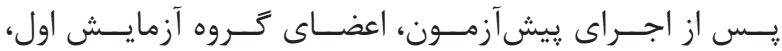

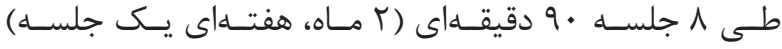

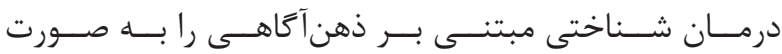

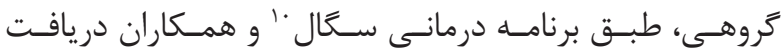

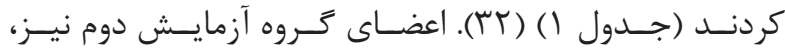

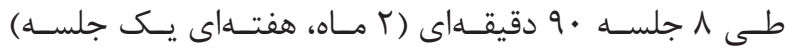

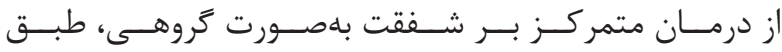

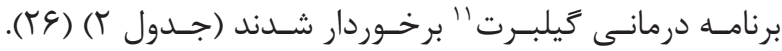

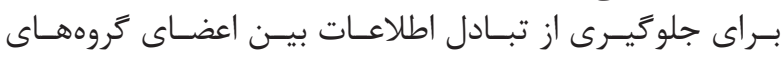

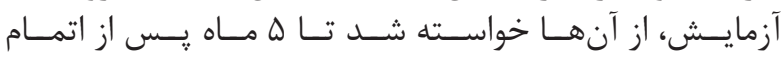

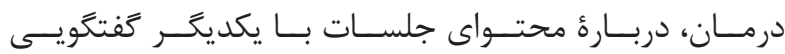

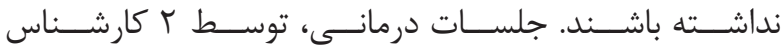

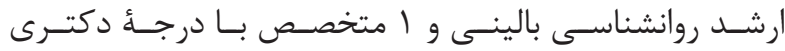

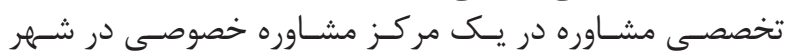

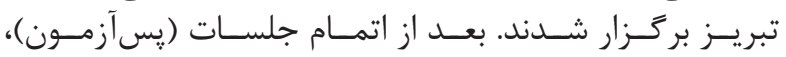

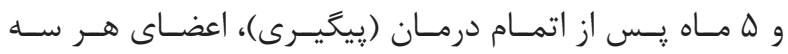

جدول ا- محتواى جلسات و بروتكل درمان شناختى مبتنى بر ذهن آكاهى

\section{شرح جلسات (هدف و موضوع)}

جلسه

هدف: آكاهى بيشتر از احساسات، افكار و حسهاى بدنى لحظه به لحظه وتجربهُ بودن در لحظه. موضوع: توضيح دربارة اهميت

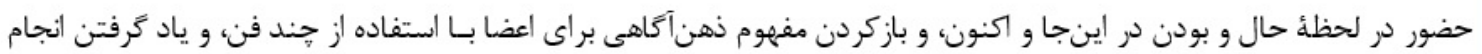
امور روزمره، همر اه با توجه كردن به دونه آنها.

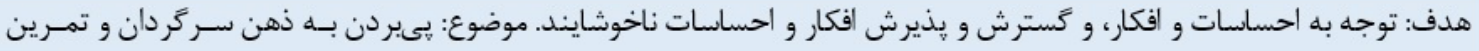

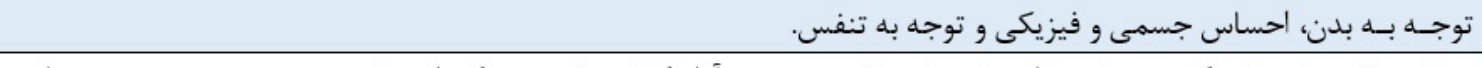

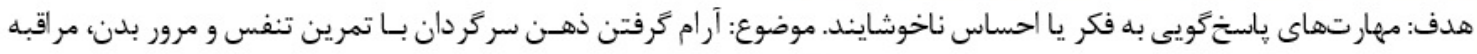

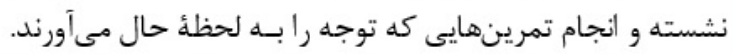

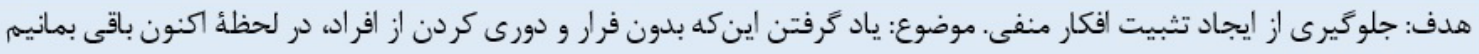

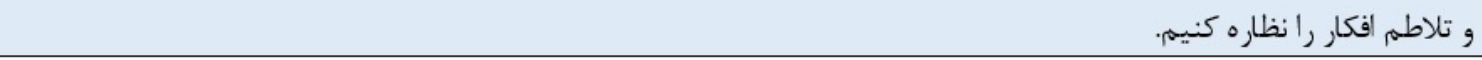
هدف: تغيير عادات قديمى فكر كردن مانند شناخت امور روزمره خودكار، بـ انظيزه بودن در كارها، بىنتيجه دانستن فعاليتها، فرار

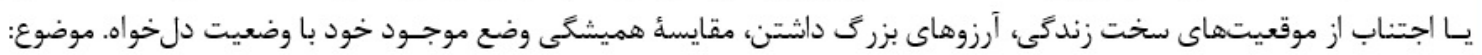

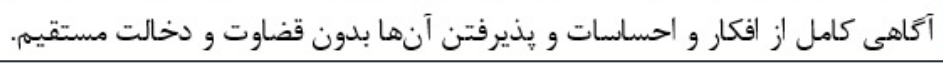
هدف: آكاه شدن از علايم هشداردهندة تابآورى و بهزيستى روانشناختى. موضوع: تغيير خلق و افكار از طريق تلقى افكار بهعنوان فقط فكر و نه واقعيت. هدف: آكاهى از تغييرات جزيى خلق. موضوع: هشيار بودن از نشانههاى كاهش تاب آورى و بهزيستى روانشناختى، و تنظيم برنامسه

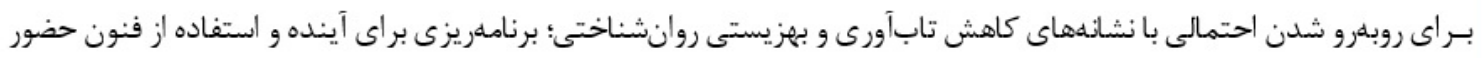
at

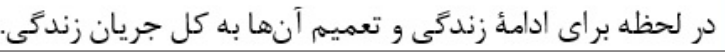




\begin{tabular}{|c|c|}
\hline ف و موضوع) & جلسه \\
\hline 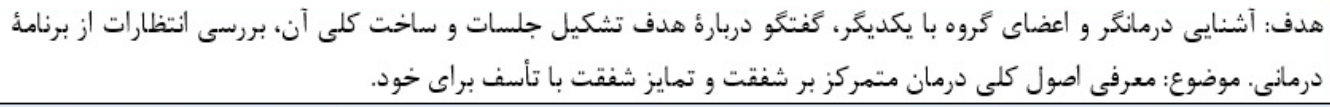 & اول \\
\hline 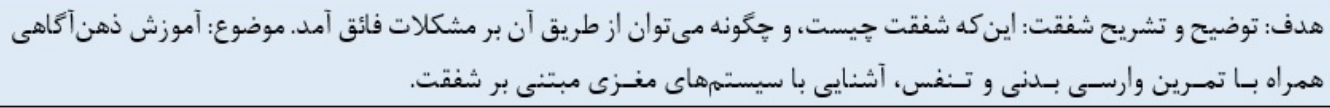 & دوم \\
\hline 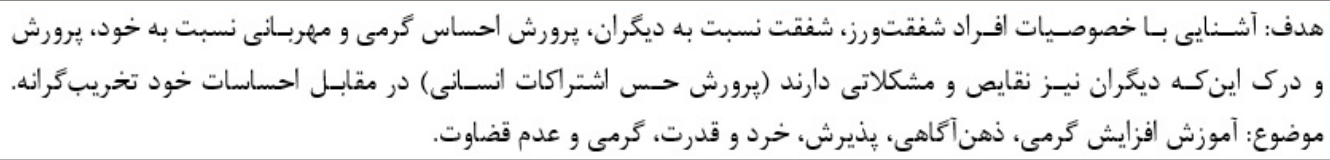 & سوم \\
\hline 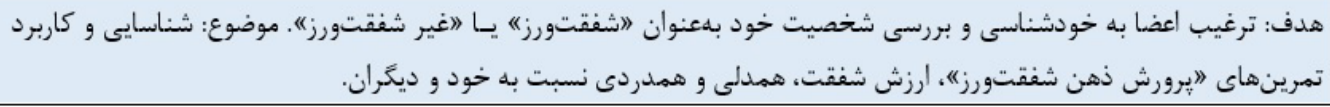 & جهارم \\
\hline روشدف: آموزش سبكهاء ابراز شفقت در زوشدى رهاى ابراز شفقت (شفقت كلامى، شفقت عملى، شفقت مقطعى و شفقت يیوسته). موضوع: بهكاركيرى & هنجم \\
\hline 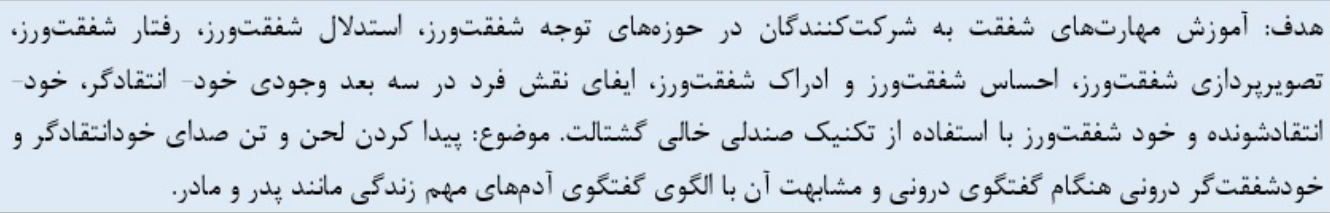 & ششم \\
\hline 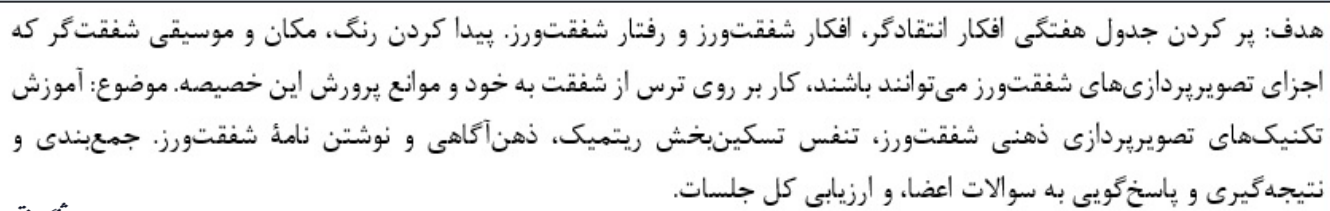 & م و هشتم \\
\hline
\end{tabular}

جدول ץ- ميانكين و انحراف معيار سن و مدت زمان ابتلا به بيمارى ام اس مردان تبريز در سال لوج| (تعداد در هر كروه • ( نفر)

\begin{tabular}{|c|c|c|c|}
\hline $\mathbf{P}$ & انحراف معيار 土 ميانكين & متغير & 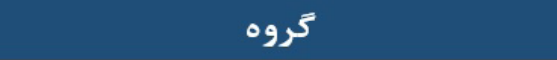 \\
\hline & $(1 / 4 \pm 1 \cdot 10$ & & درمان شناختى مبتنى بر ذهن آكاهى \\
\hline \multirow[t]{4}{*}{. Mft } & $r r / \Delta \pm r \cdot / R /$ & سن & درمان متمركز بر شفقت \\
\hline & rr/DIq./rq & & كنترل \\
\hline & $r r / \Delta \pm \cdot V / \cdot q$ & & كل \\
\hline & $\Delta / \cdot \pm \cdot \cdot|\Lambda|$ & & درمان شناختى مبتنى بر ذهن آكاهى \\
\hline \multirow[t]{3}{*}{. MFE } & $f / 1 \pm r \cdot / \varphi$ & مدت زمان ابتلا به بيمارى & درمان متمركز بر شفقت \\
\hline & $f / 1 \pm V \cdot / 19$ & & كنترل \\
\hline & $f / / \pm \varphi V / \cdot \varphi$ & & كل \\
\hline
\end{tabular}

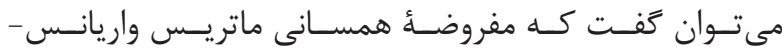

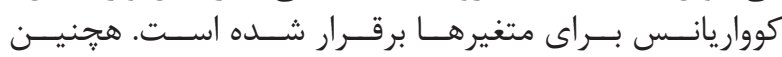

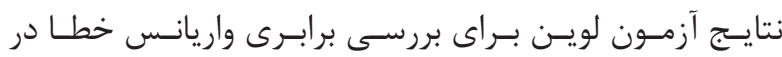

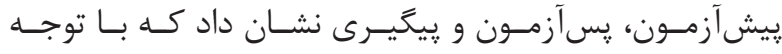

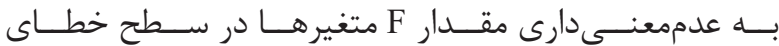

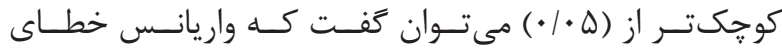

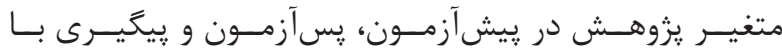

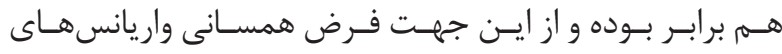

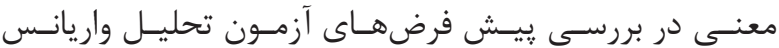

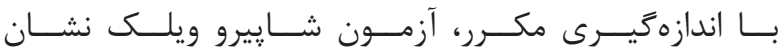

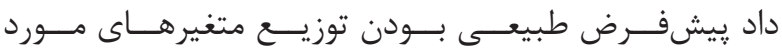

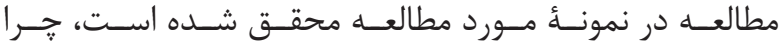

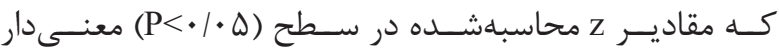

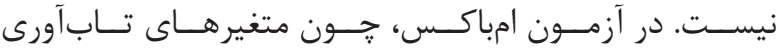

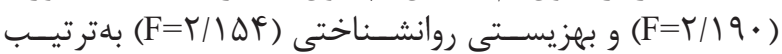

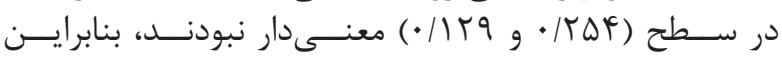


وابسـته را يذيرفتـ. يـس، ايسن پِيشفــرض نيـز برقـرار اسـت.

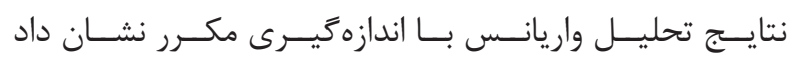

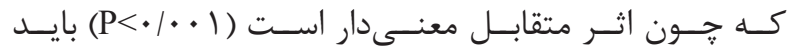

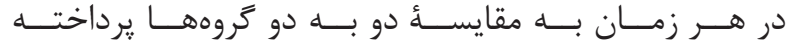

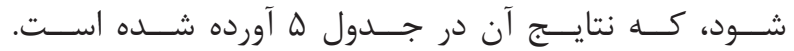

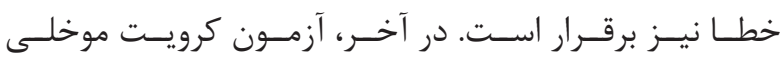

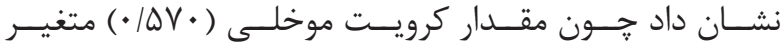

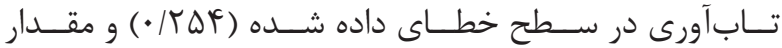

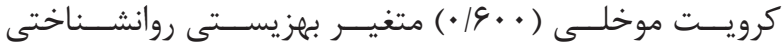

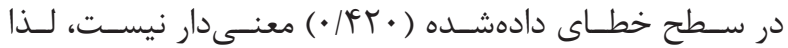

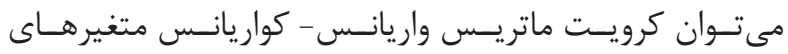

جدول F- نتايج آزمون تحليل واريانس با اندازمكيرى مكرر در بين گروههاى آزمايش و كنترل در متغيرهاى يثوهش در مراحل بيش آزمون- يسآزمون

\begin{tabular}{|c|c|c|c|c|c|c|c|c|}
\hline توان آزمون & اندازة اثر & معنى دارى & $\mathbf{F}$ & ميانكين مجذورات & درجة آزادى & مجموع مجذورات & منبع تغييرات & \\
\hline 1 & $\cdot 19 \cdot 1$ & $\cdot 1 \cdot \cdot 1$ & KFD/VAD & TrtAFF & r & $990 / 9 \wedge 9$ & آزمون & \multirow{3}{*}{ تابآورى } \\
\hline 1 & - MFG & $\cdot 1 \cdot \cdot 1$ & TY/AFV & TVF/FFF & r & $\Delta F \wedge / \wedge \wedge 9$ & كروه & \\
\hline 1 & ./Ard & $\cdot 1 \cdot \cdots 1$ & GN/DIV & qr/VqF & f & rvi/lva & آزمون:كروه & \\
\hline 1 & .1918 & $\cdot 1 \cdot \cdots 1$ & ram/f.. & RFT/K.. & r & GAF/G.. & آزمون & \multirow{3}{*}{ بهزيستى روانشناختى } \\
\hline 1 & . $/$ TOT & $\cdot 1 \cdot \cdots 1$ & TF/DTA & $\Delta \Delta \Delta / \nabla \cdots$ & r & $1111 / 4 \ldots$ & كروه & \\
\hline 1 & $\cdot / 1009$ & $\cdot 1 \cdot \cdot 1$ & AT/KVI & $98 / 1 \ldots$ & f & rNfF/f.. & آزمون: & \\
\hline
\end{tabular}

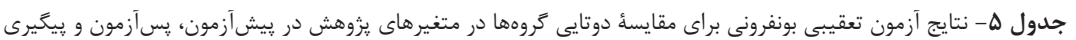

\begin{tabular}{|c|c|c|c|c|c|c|}
\hline سمطح معنى دارى & 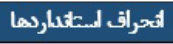 & تقاوت ميأكئين & Y F & l & \multicolumn{2}{|c|}{ متغير وليسته } \\
\hline $1 / \cdots$ & r/DIY & $\cdot / 1 \cdots$ & درمان متمركز يرشفقت & \multirow{2}{*}{ درمان شناختى مبتنى بر ذهن آكاهى } & \multirow{6}{*}{ 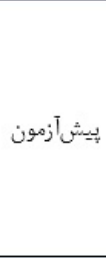 } & \multirow{36}{*}{ تايعآورى } \\
\hline $1 / \cdots$ & t/DIT & $-+/ 1+\cdots$ & كتترل & & & \\
\hline $1 / \cdots$ & t/DIT & $-* / 1 \cdots$ & درمان شناختى مبتنى ير ذهن آكاهى & \multirow{2}{*}{ درمان متمركز برشفقت } & & \\
\hline $1 / \cdots$ & r/DIT & $-* / 9+\cdot$ & كنترل & & & \\
\hline $1 / \cdots$ & T/DIT & $\cdot / 1+\cdot$ & درمان شناخَّى مبتثى بر ذهنئكاهى & \multirow{2}{*}{ كتترل } & & \\
\hline $1 / \cdots$ & T/DIT & $\cdot / 9+\cdot$ & درمان متمركز برشفقت & & & \\
\hline $1 / \cdots$ & $r / 94$. & $-1 / 0 \cdots$ & درمان متمركز برشفقت & \multirow{2}{*}{ درمان شناختى مبتنى بر ذهن آكاهى } & \multirow{6}{*}{ يس آزمون } & \\
\hline$\cdot r \Delta$ & r/qY. & $V / \Delta \cdots$ & كنترل & & & \\
\hline $1 / \cdots$ & $r / 9 r$. & $1 / \Delta \cdots$ & درمان شناختى مبتنى بر ذهن آكاهى & \multirow{2}{*}{ درمان متمركز برشفقت } & & \\
\hline .1 .9 & T/GY. & १/. & ك:ترل & & & \\
\hline $.1 \cdot r_{\Delta}$ & r/Gr. & $-V / \Delta \cdots$ & درمان شناختى مبتنى بر ذهن آكاهى & \multirow{2}{*}{ كتترل } & & \\
\hline $.1 * 9$ & $r / 94$. & $-9 / \cdots$ & درمان متمركز برشفقت & & & \\
\hline $1 / \cdots$ & $r / \Delta 9 \Lambda$ & $-1 / 9 .$. & درمان متمركز برشفقت & \multirow{2}{*}{ درمان شناختى مبتنى ير ذهن آكاهى } & \multirow{6}{*}{ ئيكيرى } & \\
\hline$\cdot 1 \cdot Y \Delta$ & $r / \Delta 9 \Lambda$ & $\mathrm{V} / \mathrm{T} \cdots$ & كترل & & & \\
\hline $1 / \cdots$ & $r / \Delta 9 \Lambda$ & $1 / 9 \ldots$ & درمان شناختى مبتنى بر ذهن آكاهى & \multirow{2}{*}{ درمان متمركز برشفقت } & & \\
\hline$+1 * \omega$ & $r / \Delta \varphi \Lambda$ & N/9.. & كتشرل & & & \\
\hline$\cdot 1 \cdot r_{D}$ & $r / \Delta 9 \Lambda$ & $-V / r+\cdots$ & درمان شناختى مبتنى بر ذهن آكاهى & \multirow{2}{*}{ كتمترل } & & \\
\hline 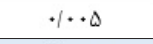 & $r / \Delta 9 \Lambda$ & $-N 9+$. & درمان راهملمجحور كوتاهمدت & & & \\
\hline $1 / \cdots$ & $r / 909$ & $.19 \cdots$ & درمان متمركز برشفقت & \multirow{2}{*}{ درمان شناختى مبتنى بر ذهن آكاهى } & \multirow{6}{*}{ يَيش آزمون } & \\
\hline $1 / \cdots$ & $r / 909$ & $1 / 9 \cdots$ & كتترل & & & \\
\hline $1 / \cdots$ & $r / 909$ & $-* / 9 * \cdot$ & درمان شناختى مبتنى بر ذهن آكاهى & \multirow{2}{*}{ درمان متمركز يرشفقت } & & \\
\hline $1 / \cdots$ & $r / 909$ & $1 / \cdots$ & كتمرل & & & \\
\hline $1 / \cdots$ & $r / 909$ & $-1 / 9+$. & درمان شناختى مبتنى بر ذهن آكاهى & \multirow{2}{*}{ كترل } & & \\
\hline $1 / \cdots$ & $r / 909$ & $-1 / \cdots$ & درمان راهحلمحور كوتامدات & & & \\
\hline $1 / \cdots$ & T/AGF & $-+/ V+\cdot$ & درمان متمركز برشفقت & \multirow{2}{*}{ درمان شناختى مبتنى بر ذهن آكاهى } & \multirow{6}{*}{ 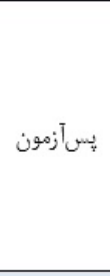 } & \\
\hline$\% * \Delta$ & Y/AGF & $1+11 \cdots$ & كترل & & & \\
\hline $1 / \cdots$ & T/AGF & $\cdot / \mathrm{r} \cdot$ & درمان شناخُتى مبتنى بر ذهن آكاهى & \multirow{2}{*}{ درمان متمركز يرشفقت } & & \\
\hline$\%+r$ & T/AGF & $1 \cdot 11 \cdots$ & كتترل & & & \\
\hline$+* \Delta$ & r/AGF & $-1+11 \cdots$ & درمان شناخَتى مبتَنى بر ذهن آكاهى & \multirow{2}{*}{ كتمرل } & & \\
\hline$\%+r$ & T/AGF & $-1+11 \cdot \cdot$ & درمان راهحلمحور كوتامدات & & & \\
\hline $1 / \cdots$ & tATA & $-+/ 1+\cdots$ & درمان متمركز يرشفقت & \multirow{2}{*}{ درمان شناختى مبتنى بر ذهن آكاهى } & \multirow{6}{*}{ بيكيرى } & \\
\hline$*+F$ & r/ATA & $1+/ 4 \cdots$ & كتترل & & & \\
\hline $1 / \cdots$ & T/AYA & $+/ 1+\cdots$ & درمان شناختى مبتنى بر ذهن آكاهى & \multirow{2}{*}{ درمان متمركز يرشفقت } & & \\
\hline$\%+r$ & T/ATA & $11 / \cdots$ & كتترل & & & \\
\hline$* * F$ & T/ATA & $-1+/ 4 \cdots$ & درمان شناختى مبتنى بر ذهن آكاهى & \multirow{2}{*}{ ك:ترل } & & \\
\hline$\%+r$ & r/ATA & $-11 / \cdots$ & درمان راهمل محور كوتامددت & & & \\
\hline
\end{tabular}




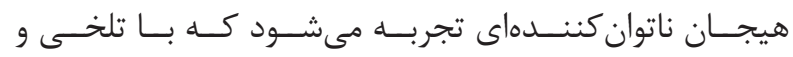

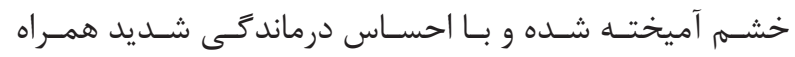

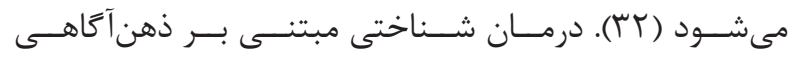

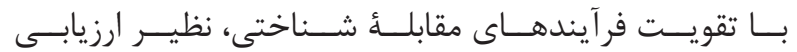

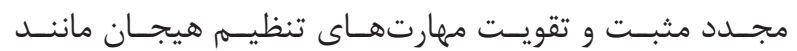

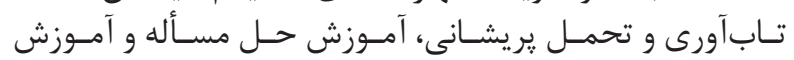

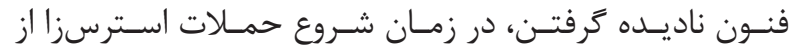

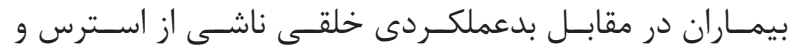

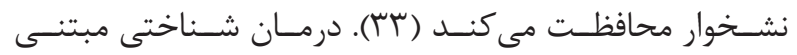

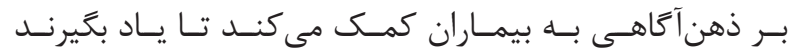

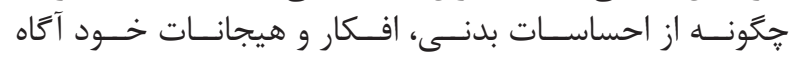

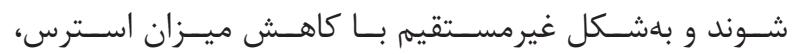

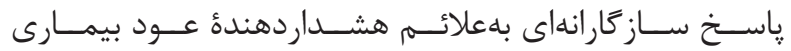

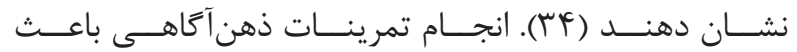

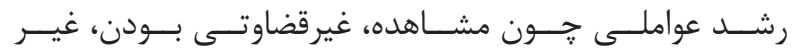

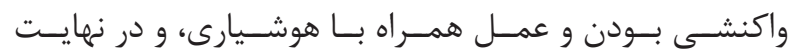

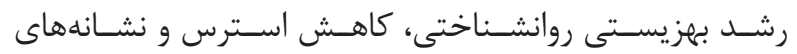

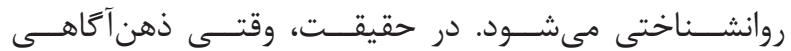

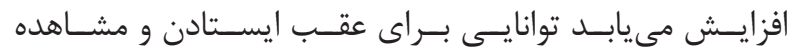

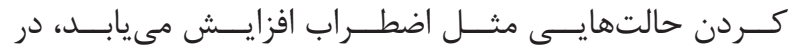

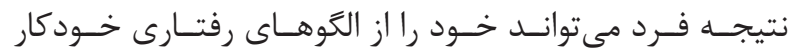

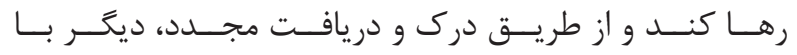

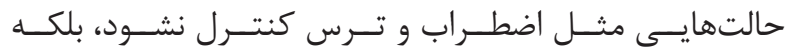

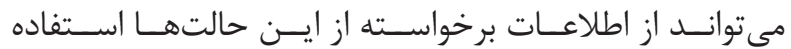

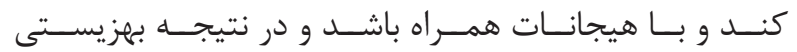

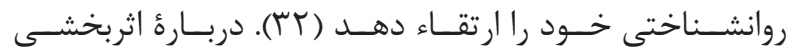

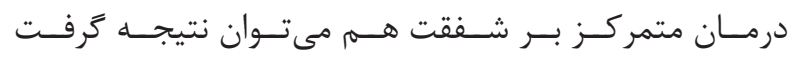

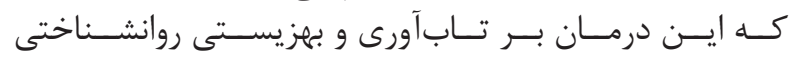

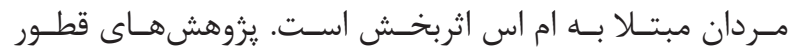

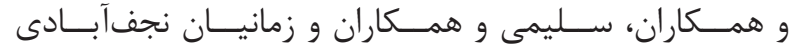

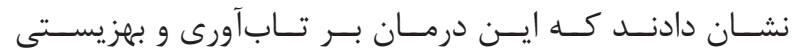

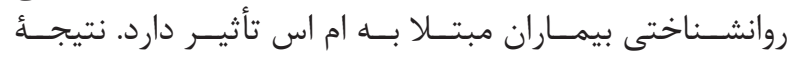

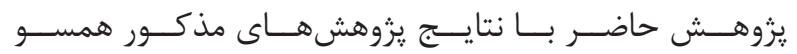

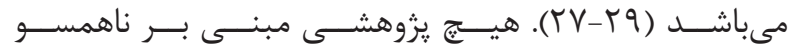

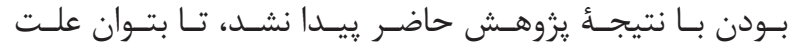

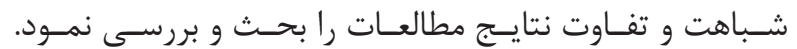

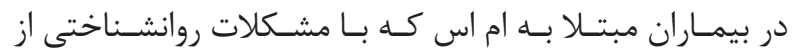

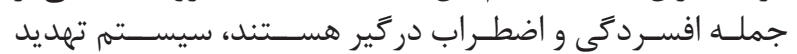

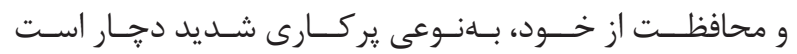

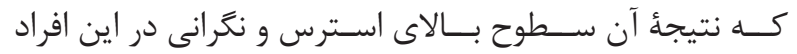

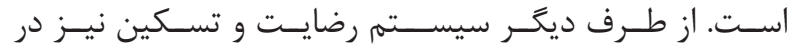

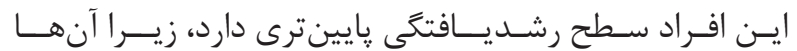

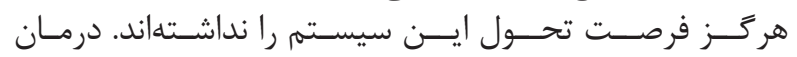

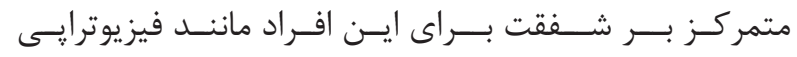

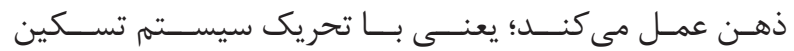

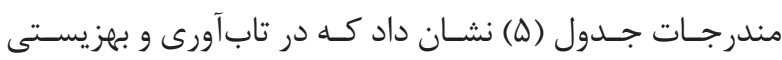

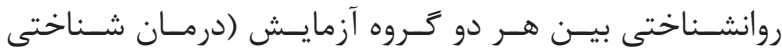

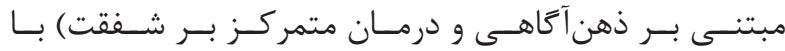

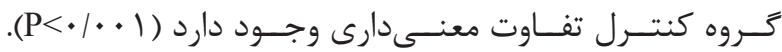

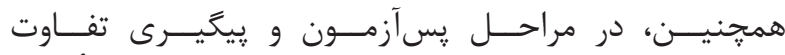

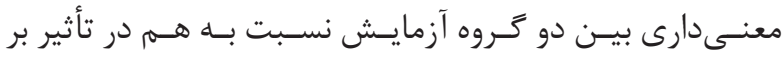

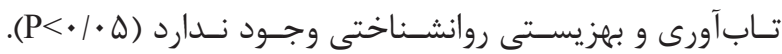

\section{بحث و نتيجه كيرى}

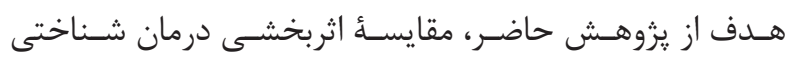

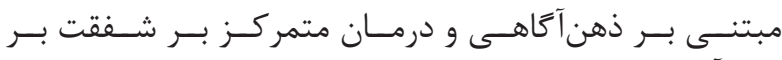

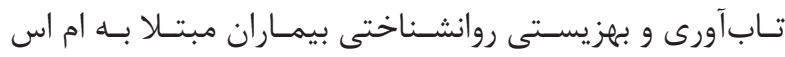

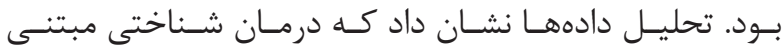

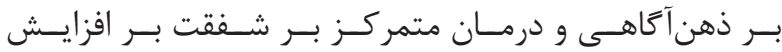

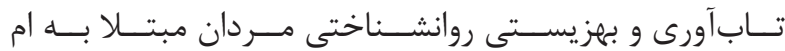

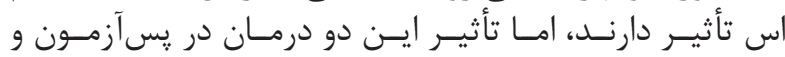

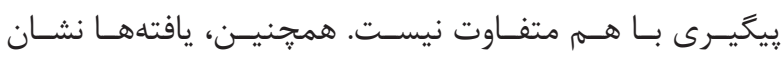

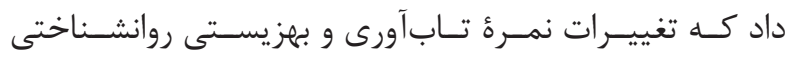

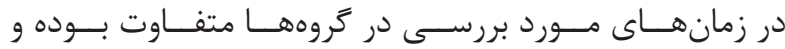

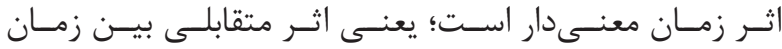

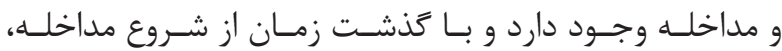

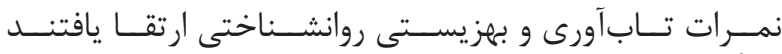

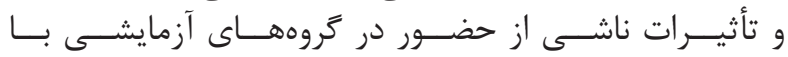

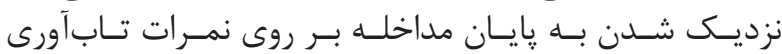

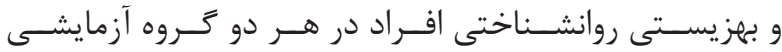

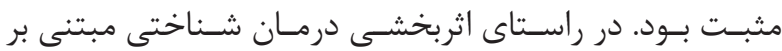

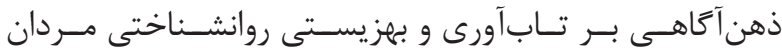

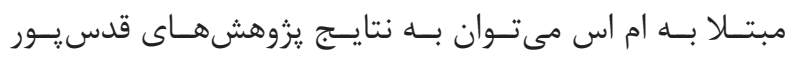

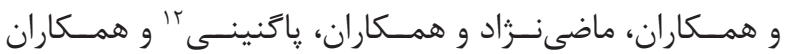

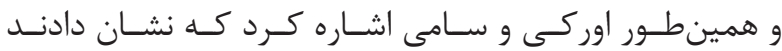

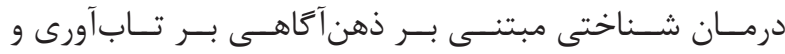

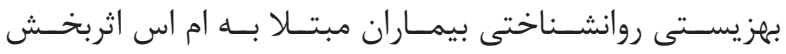

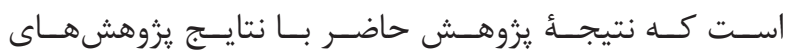

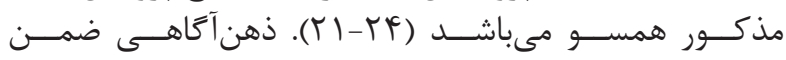

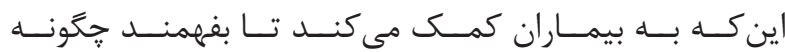

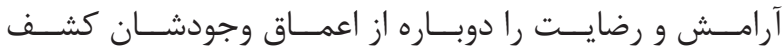

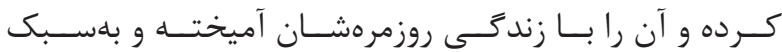

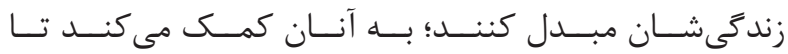

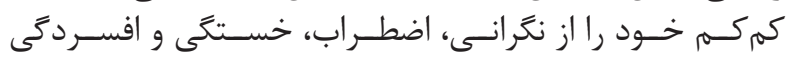

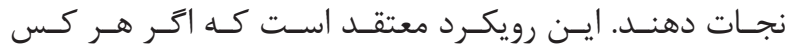

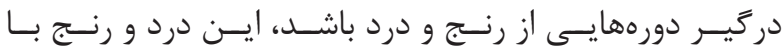

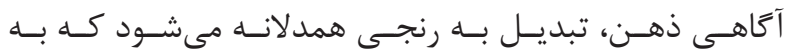

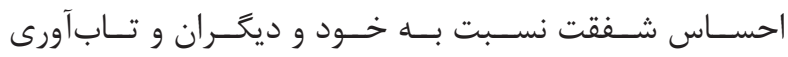

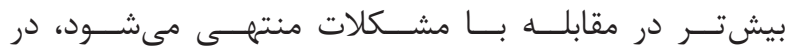

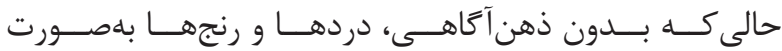


روشهــاى منحصــر بــهـ فــرد خـــود در افزايسـش تـابآورى و

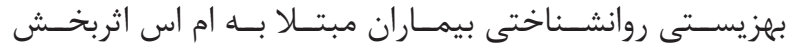

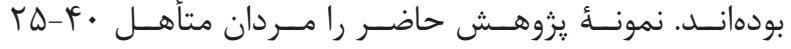

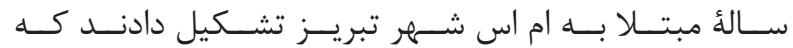

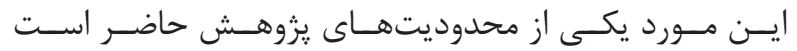

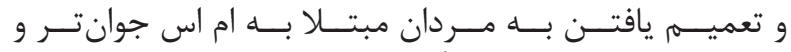

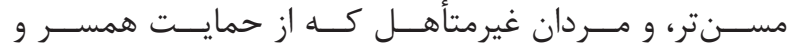

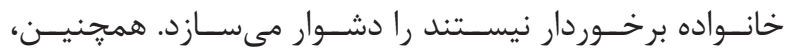

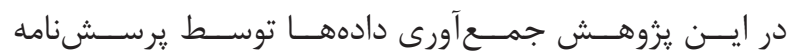

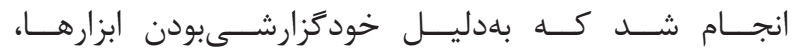

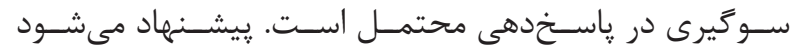

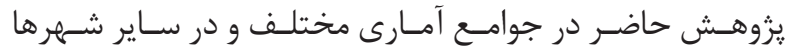

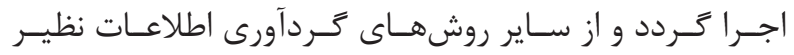

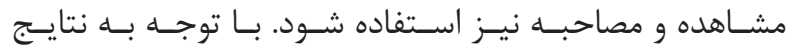

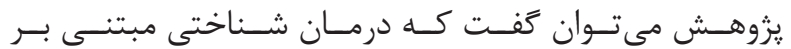

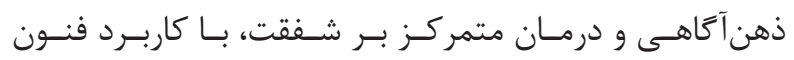

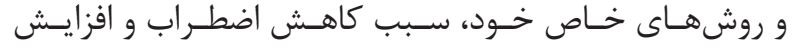

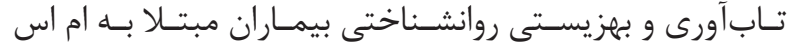

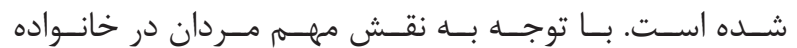

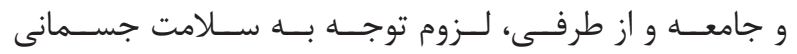

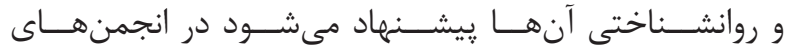

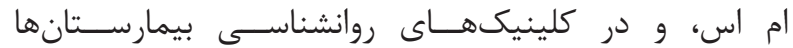

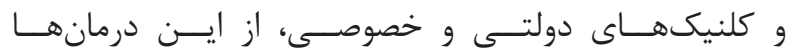

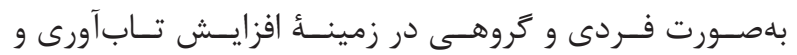

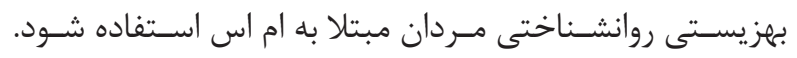

$$
\text { تشكر و قدردانى }
$$

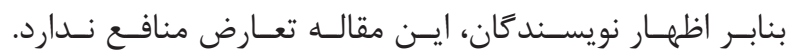

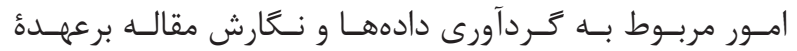

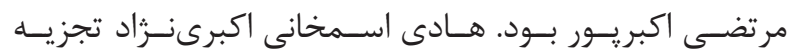

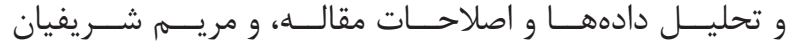

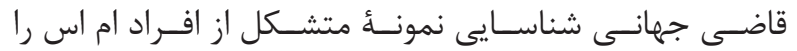

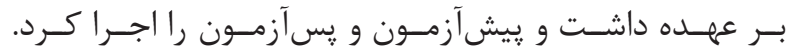

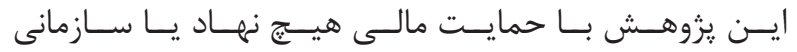

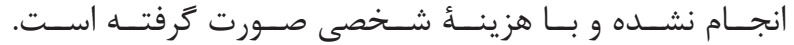

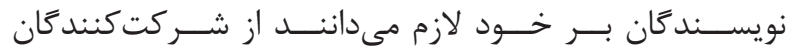

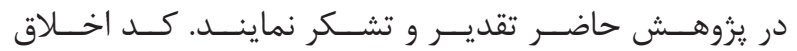

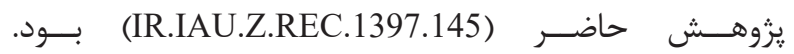

1. National Multiple Sclerosis Society. WHAT IS MS? [Cited 2019 Oct 22]. Available from: https://www.nationalmssociety.org

2. Talebzadeh M, Asemi M. National Assessment of patients with Multiple Sclerosis. Fourth International Congress of MS: Iran. 2010; 152-5. [Persian].

3. McCabe PM. Mood and self-esteem of

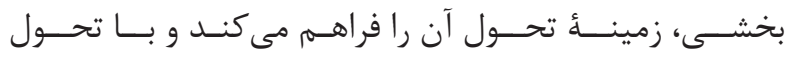

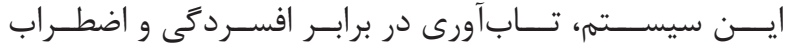

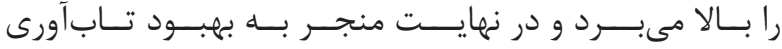

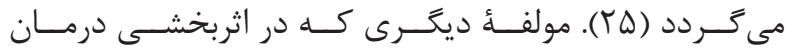

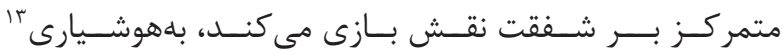

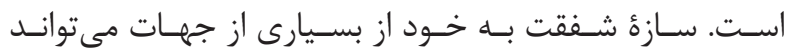

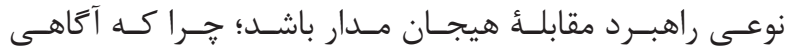

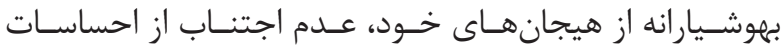

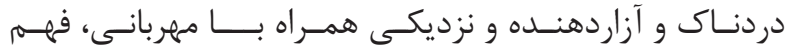

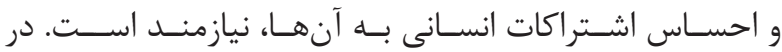

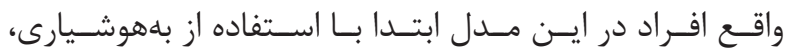

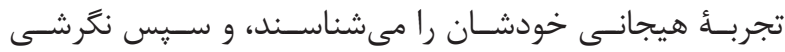

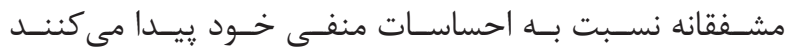

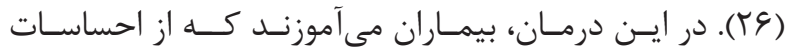

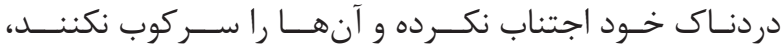

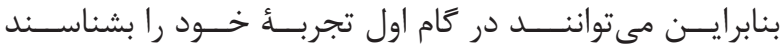

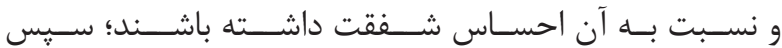

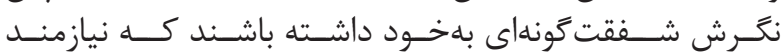

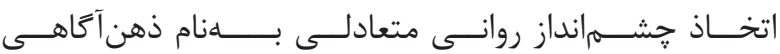

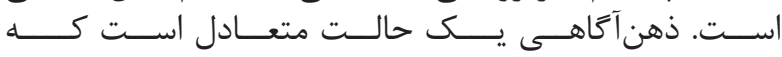

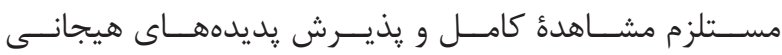

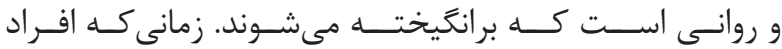

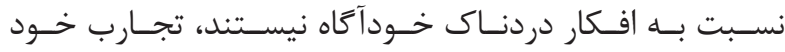

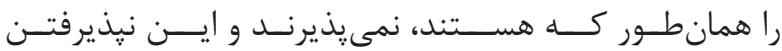

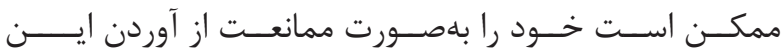

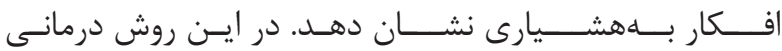

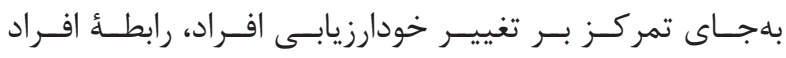

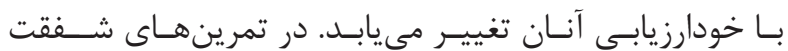

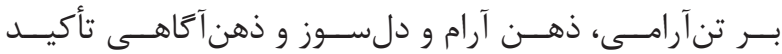

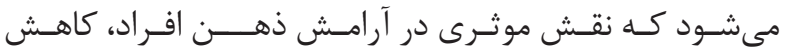

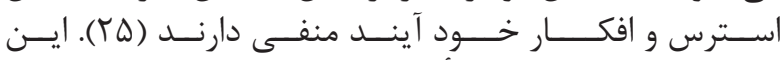

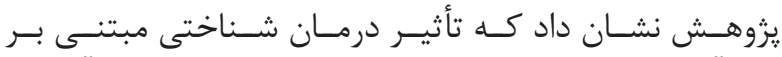

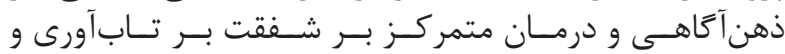

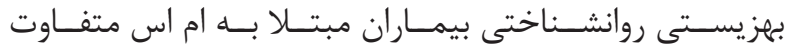

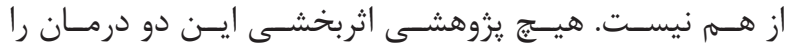

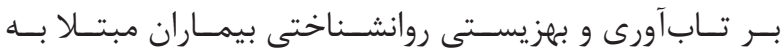

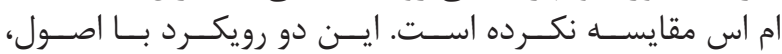

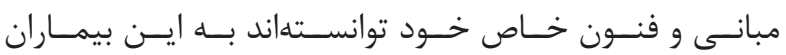

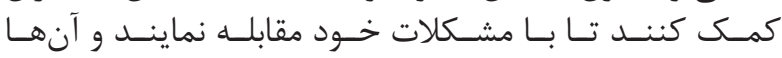

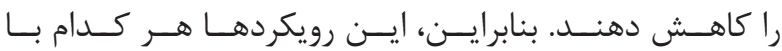

منابع

persons with multiple sclerosis following an exacerbation. J Psychosomat Res. 2005; 59: 161-6.

4. KhezriMoghadam N, Ghorbani N, Bahrami H, Rostami R. Effectiveness of group therapy in reducing psychological symptoms in patients with MS. J Clin Psychol. 2012; 4(1): 13-22 . [Persian].

5. Ziaian T, De Anstiss H, Georgia A, Baghurst P, Sawyer 
M. Resilience and its association with depression, emotional and behavioral problems, and mental health service utilization among refugee adolescents living in South Australia. IJPR. 2012; 22: 9-17.

6. Dalmida SG, Koenig HG, Holstad MM, Wirani MM. The psychological well-being of people living with HIV/AIDS and the role of religious coping and social support. Int J Psychiatry Med. 2013; 46(1): 57-83.

7. Oraki M, Sami P. The Effect of Mindfulness Integrated Behavior- Cognitive Therapy on psychological wellbeing and quality of life among multiple sclerosis patients. HPJ. 2017; 5(20): 34-47. [Persian].

8. Conner K M, Davidson J R. Development of a new resilience scale: The Conner - Davidson Resilience Scale (CD-RISC). DEPRESS ANXIETY. 2003; 18(2): 76-82.

9. Pinquart M. Moderating effect of dispositional resilience on association between hassles and psychological distress. JADP. 2009; 30: 1-8.

10. Catalano D, Chan F, Wilson L. The buffering effect of resilience on depression among individuals with spinal cord injury. JPRMH. 2011; 56(3): 200-11.

11. Bauer H, Emeny R T, Baumert J, Ladwig $\mathrm{K}-\mathrm{H}$. Resilience moderates the association between chronic pain and depressive symptoms in the elderly. Eur. J. Pain. 2016; 20(8): 1253-65.

12. Tajikzade F, Sadeghi R, Raees karimian F. The comparison of resilience, coping style and pain catastrophizing in cancer patients and normal people. JAP. 2016; 7(3): 38-48. [Persian].

13. Weiss $\mathrm{L}$ A, Westerhof $\mathrm{G} \mathrm{J}$, Bohlmeijer ET. Can We Increase Psychological Well-Being? The Effects of Interventions on Psychological Well-Being: A Meta-Analysis of Randomized Controlled Trials. Plos One. 2016; 11(6): e0158092.

14. Ryff CD. Articolo Target. Psychological well-being and health: Past, present and future. PIlla. 2016; 1: 7-26.

15. Kleiman EM, Chiara AM, Liu RT, JagerHyman SJ, Choi JY, Alloy DB. Optimism and well-being: A prospective multi-method and multi-dimensional examination of optimism as a resilience factor following the occurrence of stressful life events. Cogn Emot. 2018; 31(2): 269-83.

16. Schapiro RT. Managing the symptoms of multiple sclerosis. New York: Demos; 2014: 123-4.

17. Rattue P. Stress reduction therapy could significantly
helpMSpatients.MedicalNews Today.[Cited2014Oct21].

18. Emanuel AS, Updegraff JA, Kalmbach AD, Ciesla $J$ A. The role of mindfulness facets in affective forecasting. PIDJ. 2010; 49: 815-18.

19. McCarney RW, Schulz J, Grey AR. Effectiveness of mindfulness-based therapies in reducing symptoms of depression: A meta-analysis. EJPC. 2012; 14(3): 279-99.

20. Michalak J, Burg J, Heidenreich T. Don't Forget Your Body: Mindfulness, Embodiment and the Treatment of Depression. Mindfulness. 2012; 3(3): 190-9.

21. Ghodspour Z, Najafi M, Rahimian Boogar I. Effectiveness of Mindfulness-Based Cognitive Therapy on Psychological Aspects of Quality of Life, Depression, Anxiety, and Stress Among Patients With Multiple Sclerosis. JPCP. 2018; 6(4): 215-22. [Persian].

22. Maazinezhad M, Arefi M, Farnoodi F. The Effectiveness of Mindfulness-Based Cognitive Group Therapy in Reducing Perceived Stress in Patients with Multiple Sclerosis. J Clin Res Paramed Sci. 2018; 7(1): 1-5. [Persian].

23. Pagnini F, Phillips D, Bosma CM, Reece A, Langer E. Mindfulness, physical impairment and psychological well-being in people with amyotrophic lateral sclerosis. Psychol Health. 2015; 30(5): 503-17.

24. Oraki M, Sami P. Investigating the Effectiveness of Mindfulness-Based Cognitive Therapy on the Perception of Disease and its Severity in Patients with Multiple Sclerosis. So Cogn. 2016; 5(2): 107-19. [Persian].

25. Ashworth F, Gracey F, Gilbert P. Compassion focused therapy after traumatic brain injury: Theoretical foundationsandacaseillustration.BIJ.2011;12(2):128-39.

26. Gilbert P. Introducing compassion-focused therapy. BJPsych Advances. 2009; 15(3): 199-208.

27. Ghator Z, Pouryahya S, Davarniya R, Salimi A, ShakaramiM. TheEffectofCompassion-Focused Therapy (CFT) on Resiliency of Women with Multiple Sclerosis (MS). Armaghane danesh. 2018;23(3):350-63. [Persian].

28. Salimi A, Arsalandeh F, Zahrakar K, Davarniya R, Shakarami M. The Effectiveness of Compassion-Focused Therapy on Mental Health of Women with Multiple Sclerosis.HorizonMedSci.2018;24(2):125-31.[Persian].

29. Zamanian Najafabdi M.The effectiveness of compassion-based treatment on dysfunctional attitudes, Self-criticism and compassion for the patients with M. S. Master's Degree in Clinical Psychology, Islamic Azad University, Najafabad Branch, 2018: 94-5. [Persian]. 
30. Ahangarzadeh Rezaei S. Rasoli M. Psychometric Properties Of the perstan version of "Conner-Davidson Resilience Scale" in adolescents with cancer. J Urmia Nurs Midwifery Fac 2015; 13(9): 739-47. [Persian].

31. Bayani AA, Mohammad Koochekya A, Bayani A. Reliability and Validity of Ryff's Psychological Well-being Scales. IJPCP. 2008; 14(2): 146-51.
32. Segal ZV, Williams JM, Teasdale JD. Mindfulness Based cognitive therapy for depression. 3nd Ed. New York: The Guilford Press 2013: 86.

33. Williams M, Penman D. Mindfulness: A practical guide to finding peace in a frantic world. 1en ed. Piatkus Books, 2012:45-46. Garland E, Gaylord S, Park J. The role of mindfulness in positive reappraisal. Explore (NY) 2009; 5: 37-44. 